\title{
Association of body mass index and dietary restraint with changes in eating behaviour throughout late childhood and early adolescence: a 5-year study
}

\author{
Sherri Bisset ${ }^{1, *}$, Lise Gauvin ${ }^{1}$, Louise Potvin ${ }^{1}$ and Gilles Paradis ${ }^{2}$ \\ ${ }^{1}$ Department of Social and Preventive Medicine, GRIS (Groupe de recherche interdisciplinaire en santé) and Centre \\ de recherche Léa-Roback sur les inégalités sociales de santé de Montréal, University of Montréal, Montréal, Québec, \\ Canada: ${ }^{2}$ Institut national de santé publique du Québec and Department of Epidemiology, Biostatistics and \\ Occupational Health, McGill University, Montreal, Québec, Canada
}

Submitted 24 October 2005: Accepted 17 August 2006: First published online 7 March 2007

\begin{abstract}
Objectives: To describe patterns of dietary behaviours specific to low quality snacking, fruit and vegetable, and fast food consumption during the transition from childhood to adolescence and to examine how these behaviours are associated with tendencies towards dietary restraint and the occurrence of overweight and obesity in midadolescence.

Design: A 5-year follow-up of self-reported eating. Hierarchical linear modelling was utilised to explore the relationship between dietary changes and body mass index (BMI) and dietary restraint while controlling for physical activity and smoking.

Setting: The sample was derived from students participating in the Quebec Heart Health Demonstration Project, and represents rural, suburban and inner city youths.

Subjects: A sample of 561 girls and 627 boys in the fourth, sixth, seventh and ninth grades. Results: Overall the sample was characterised by a decrease in fruit and vegetable consumption and increase in low quality snacking, and a decrease in fast food consumption over the 5-year follow-up. Dietary restraint and BMI were found to be associated with dietary behaviour. Lower than average dietary restraint was associated with a lower frequency of fast food consumption and greater increase in low quality snacking over the 5-year period. Higher than average dietary restraint was associated with lesser frequency of low quality snacking at baseline. Having a BMI in the obese range was associated with more frequent fast food consumption in the fourth grade and a more rapid drop in fast food consumption across the 5-year period.

Conclusions: Dietary behaviours are associated with the psychological construct dietary restraint and with weight status in this population of adolescents.
\end{abstract}

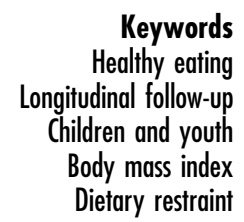

Keywords dingl follow-up Children and youth Dietary restraint
Current descriptions of dietary behaviours among youth are troubling and include underconsumption of fruit and vegetables and overconsumption of sugars and fats ${ }^{1-3}$. The latter behaviours appear to have worsened over the past decades ${ }^{4,5}$. Although dietary behaviours are implicated in the obesity epidemic ${ }^{6,7}$, longitudinal studies exploring childhood predictors of adiposity have not demonstrated clear and consistent relationships between diet and obesity 8,9 . Psychological research on childhood diet has shown attitudes surrounding weight control to be implicated in youth dietary behaviours ${ }^{10,11}$ and weight gain $^{12,13}$. Understanding how youth dietary behaviours evolve over time and their concomitant health outcomes can contribute to our knowledge of the obesity epidemic and orient future nutrition interventions. This report describes patterns of eating behaviours during the transition from childhood to adolescence and examines their association with weight status and dietary restraint in mid-adolescence.

\section{Existing knowledge about patterns of dietary bebaviours}

Compared with their younger counterparts, dietary behaviours among older adolescents are increasingly influenced by their peers ${ }^{14}$, the food to which they have access outside of the home $e^{1,15}$, body image and body weight concerns ${ }^{16}$. Although there is a dearth of longitudinal evidence on adolescent dietary behaviours, existing data suggest a decrease in fruit and vegetable consumption from childhood to younger adolescence ${ }^{17}$ as well as during mid-adolescence to young adulthood ${ }^{18}$. An overall decrease in energy from fat and an increase in energy from simple sugars have been shown among adolescent girls ${ }^{14}$. 
Dietary behaviours have familial roots, and particular patterns of behaviours have been associated with the development of obesity. For example, role modelling influences preferences for fruits and vegetables ${ }^{19}$. The preference for energy-dense foods is influenced by past tasting experience and perceived satiety from these foods ${ }^{20}$. In particular, child-feeding control styles have been shown to influence the self-regulation of energy intake based on internal cues of satiety and hunger ${ }^{21}$.

Psychological research describes a range of maladaptive eating styles which correspond to a lack of responsiveness to internal hunger and satiety cues $^{22}$. One such style, dietary restraint, has been identified among children and adolescents ${ }^{11,13}$. Restrained eaters are individuals who struggle to maintain control over their food intake and weight and who demonstrate stress-induced hyperphagic eating behaviours ${ }^{23,24}$. Dietary restraint has been documented among females as early as 5 years of age ${ }^{11}$, and among pre-adolescent males and females between the ages of 9 and 11 years ${ }^{25-27}$. It has been associated with a number of adverse psychosocial outcomes among teens, including depression, feelings of worthlessness, body dissatisfaction and social anxiety ${ }^{28,29}$.

\section{The current investigation}

The objective of this longitudinal study was two-fold: (1) to describe patterns of dietary behaviours during the transition from childhood to adolescence; and (2) to examine how these patterns are associated with tendencies towards dietary restraint and the occurrence of overweight and obesity in mid-adolescence. This study is part of a 5-year longitudinal study aimed at exploring how behaviour-specific environments and family characteristics might be associated with heart health behaviours (dietary consumption, physical activity and cigarette smoking) during pre- and early adolescence ${ }^{30,31}$.

\section{Methods}

\section{Participants}

Grade four classes were recruited from 14 rural, five suburban and 13 urban elementary schools in control and experimental sites of the Quebec Heart Health Demonstration Project $^{30,31}$. A total of 1274 fourth grade students for whom parental consent was obtained provided baseline data in March 1995. This represented participation rates of 74, 71 and 41\%, respectively, from rural, suburban and urban communities. Low participation in urban communities was possibly due to a high proportion of subjects from families who spoke neither French nor English. New students present for the follow-up survey in 1997 ( $n=377$ ) were added to the original cohort. A total of 1307 grade 6 pupils were surveyed in 1997, and this cohort was surveyed again in 1998 (grade $7, n=1189$ ) and 2000 (grade 9, $n=1354$ ). A total of 2019 students were followed-up on a least one of the four surveys. After excluding students providing unusable data on diet, gender, place of residence, physical activity or smoking, weight, height or dietary restraint, the final results are based upon a total of 1188 participants and 3417 repeated measures. Estimates at the fourth, sixth, seventh and ninth grade are based on samples of 812, 804, 790 and 1011 participants. The mean and standard deviation of dietary restraint, body mass index (BMI), sex and smoking status did not differ between the group which was excluded and those retained in the cohort. Similarly, mean and standard deviation for BMI and dietary restraint did not differ between groups reporting dietary data at four, three, two and one time point. Participant characteristics are provided in Table 1.

\section{Measures}

\section{Eating behaviour}

Eating behaviour was measured with the same selfadministered food-frequency questionnaire at each data collection point. Food items and response scales were adapted from the cross-national Health Behaviour among School Children (HBSC) questionnaire ${ }^{32}$. Participants were asked to report their weekly consumption of 35 different types of foods, including four items on fruit and vegetable consumption: (1) fruits, (2) cooked vegetables, (3) raw vegetables or (4) green salad ('not at all', 'one or several times' and 'each day', coded 0, 3.5 and 7 times per week, respectively); three items on low quality snacking: (1) doughnuts, cakes or pastries, (2) chips or (3) candy (sweets) or chocolate bars ('not at all', 'one or several times' and 'each day', coded 0, 3.5 and 7 times per week, respectively); and four items pertaining to fast food consumption: (1) French fries or poutine (a popular local fast food consisting of French fries, sauce and cheese curds), (2) hamburgers, (3) hot dogs or (4) fried chicken ('not at all', 'once or twice per week' and ' 3 or more times per week', coded 0, 1.5 and 3 times per week, respectively). Responses were then summed to create an index of weekly consumption for each of fruit and vegetable consumption, low quality snacking and fast food consumption. The items relevant to these categories

Table 1 Characteristics of participants $(n=1188)$ providing dietary data on at least one occasion

\begin{tabular}{llr}
\hline Variable & \multicolumn{1}{c}{ Category } & $n(\%)$ \\
\hline Sex & Males & $627(52.8)$ \\
& Females & $561(47.2)$ \\
Site & Rural & $459(38.6)$ \\
& Suburban & $392(33.0)$ \\
BMI & Urban & $337(28.4)$ \\
& Normal weight or underweight & $954(80.3)$ \\
\multirow{3}{*}{ Dietary restraint } & $147(12.4)$ \\
& Overweight & $87(7.3)$ \\
& Obese & $390(32.8)$ \\
& Low & $408(34.3)$ \\
& Average & $390(32.8)$ \\
\hline
\end{tabular}

$\mathrm{BMI}$ - body mass index. 
of low quality snacking and fruit and vegetable consumption have shown good agreement for next day retest ( $\kappa$ values all $>0.45$ ) and a good validity using a single 24-hour dietary recall and a 7-day food-frequency questionnaire (correlations ranging from 0.52 to 0.82$)^{33}$. Furthermore, the food-frequency questionnaire is recognised as an appropriate data assessment method for largescale studies ${ }^{34}$ and as suitable for youth from the age of $10^{35}$. Food item categories similar to those reported in this study have been used to assess dietary habits of Canadian youth. Fatty food intake, fruit and vegetable intake, and snacking, each derived from a self-reported foodfrequency questionnaire, have been used as proxies for unhealthy dietary behaviours among adolescents ${ }^{36}$.

\section{$B M I$}

BMI was estimated by calculating the ratio of self-reported weight to the squared value of self-reported height $\left(\mathrm{kg} \mathrm{m}^{-2}\right)$ and was recorded only in the final year of the follow-up when the participants were in the ninth grade. The classification of youth into weight status categories for our study is based upon sex- and age-specific BMI cut-offs established by the Centers for Disease Control and Prevention growth charts ${ }^{37}$. BMI is considered an appropriate measure of fatness in adolescence ${ }^{38,39}$, and self-reported heights and weights have been shown to provide reliable BMI estimates for youth ${ }^{40-42}$. Some studies have found BMI to underestimate overweight and obesity when reliant upon self-reports ${ }^{2}$. For the purposes of this study, however, the use of self-reported height and weight was deemed appropriate since the purpose was to determine an association and not to establish prevalence.

\section{Dietary restraint}

Similarly to BMI, restrained eating was evaluated only during the final year of the study. Questions on restrained eating were taken from the Dutch Eating Behavior Questionnaire (DEBQ) ${ }^{43}$. Both the French validated version $^{44}$ and the original English version were used. The DEBQ contains 10 questions to assess levels of restrained eating. Questions ask about changes in eating behaviours as a direct response to weight concerns, such as 'if you gain weight, do you make an effort to eat less than usual?'. Questions are scored from 1 to 5, with 1 representing 'never' and 5 'always'. The 10 items are averaged to produce a restrained eating score. Internal consistency of the scale was high, with a Cronbach $\alpha$ of 0.93 The DEBQ scale has been reported to be better suited to assess eating style among children and adolescents than more complex scales requiring information about weight history ${ }^{45,46}$.

Physical activity and smoking were reported throughout the study; however, we only used data reported during the final year of the follow-up. Physical activity during the previous week was assessed dichotomously as vigorous (i.e. running, hockey, aerobics, basketball), moderate (i.e. tennis, volleyball, football) or mild (i.e. walking, bowling) activity three or more times for 15 min or more. Participants were categorised as regular smokers (smoking at least on a weekly basis), experimental smokers (smoking at some point during the previous month or years) or non-smokers (never smoking).

\section{Procedures}

Each of the school boards facilitated data collection by endorsing the research initiative. Data were collected in classrooms by self-administered questionnaires under the supervision of a trained interviewer. For the final collection period, a confidential master list with children's names and schools was used to trace children into high schools along with contact information provided by the parents at baseline. At the two final data collection points, subjects were aged $\sim 14$ and 16 years and could provide written informed consent. The human research ethics committee of the Faculty of Medicine of the University of Montreal approved the study.

\section{Statistical analysis}

Hierarchical linear modelling analyses (HLM, version 6.02) were applied to the longitudinal data set, first to describe patterns of each of the three food frequency consumption indices (i.e. fruit and vegetable, low quality snacking and fast food) across the 5-year period and next to determine if patterns of eating behaviours during that time were associated with dietary restraint and/or BMI measured in the fifth year of data collection. That is, we first estimated a null model to determine the intraclass correlation coefficient (ICC) and the plausible value ranges to describe the variation for each of the three food frequency indices. Next, we modelled changes in each food frequency index across time by adding a fixed time variable which permitted the establishment of a linear growth trend across the 5-year period. The baseline represented estimated food frequency when children were in the fourth grade or $\sim 10$ years old. Quadratic changes across time (i.e. squared value of linear trend representing accelerated change) were also tested for each index. Only changes in fast food consumption were curvilinear. Therefore, the quadratic effect was only kept in this model. We then controlled for sex and place of residence by adding dummy variables as moderators of the baseline intercept and the time variable slopes. Nonsignificant coefficients were subsequently removed from the model. Next, BMI (or dietary restraint) was added to each of the three food frequency models as moderators of the baseline intercept and time slopes. Finally, the dummy variables accounting for smoking and physical activity were added as moderators of both the baseline intercept and the time slope to control for potential confounding. Only results for the final models are reported in Tables $2-4$.

During model construction, the number of cases available to be included in the model was reduced due to missing information. During the process of model construction, results of model testing on larger and smaller 
Table 2 Results for model of weekly frequency of fruit and vegetable and its association with dietary restraint and BMI

\begin{tabular}{|c|c|c|c|c|}
\hline \multirow{3}{*}{ Fixed effect } & \multicolumn{2}{|c|}{ Dietary restraint } & \multicolumn{2}{|l|}{ BMI } \\
\hline & Coefficient (SE) & $t$ & Coefficient (SE) & $t$ \\
\hline & \multicolumn{2}{|c|}{ Final estimation of fixed effects } & \multicolumn{2}{|c|}{ Final estimation of fixed effects } \\
\hline Baseline intercept, $\gamma_{00}$ & $17.42(0.60)$ & 29.26 *** & $16.97(0.55)$ & 30.59 *** \\
\hline Girls, $\gamma_{01}$ & $0.67(0.32)$ & $2.10^{\star}$ & $0.66(0.33)$ & $1.98^{\star}$ \\
\hline Vigorous exercise, $\gamma_{02}$ & $-0.71(0.41)$ & -1.73 & $-0.69(0.41)$ & -1.67 \\
\hline Moderate exercise, $\gamma_{03}$ & $-0.79(0.45)$ & -1.75 & $-0.81(0.45)$ & -1.78 \\
\hline Mild exercise, $\gamma_{04}$ & $-0.43(0.39)$ & -1.08 & $-0.45(0.39)$ & -1.14 \\
\hline Rural setting, $\gamma_{05}$ & $1.19(0.37)$ & $3.17^{\star \star}$ & $1.22(0.37)$ & $3.29^{\star \star \star}$ \\
\hline Suburban setting, $\gamma_{06}$ & $1.26(0.39)$ & $3.20^{\star \star}$ & $1.25(0.39)$ & $3.19^{\star \star}$ \\
\hline Experimental smoker, $\gamma_{07}$ & $-0.17(0.45)$ & -0.38 & $-0.20(0.43)$ & -0.46 \\
\hline Regular smoker, $\gamma_{08}$ & $-0.13(0.52)$ & -0.25 & $-0.14(0.52)$ & -0.28 \\
\hline Lower than average dietary restraint, $\gamma_{09}$ & $-0.79(0.46)$ & -1.67 & - & - \\
\hline Higher than average dietary restraint, $\gamma_{010}$ & $-0.60(0.46)$ & -1.22 & - & - \\
\hline Overweight, $\gamma_{09}$ & - & - & $0.23(0.58)$ & 0.40 \\
\hline Obese, $\gamma_{010}$ & - & - & $-0.28(0.77)$ & -0.36 \\
\hline Linear change, $\gamma_{10}$ & $0.10(0.13)$ & 0.76 & $0.11(0.12)$ & 0.92 \\
\hline Vigorous exercise, $\gamma_{11}$ & $0.02(0.10)$ & 0.20 & $0.02(0.10)$ & 0.16 \\
\hline Moderate exercise, $\gamma_{12}$ & $-0.11(0.12)$ & -0.97 & $-0.11(0.11)$ & -1.05 \\
\hline Mild exercise, $\gamma_{13}$ & $-0.05(0.09)$ & -0.53 & $-0.06(0.09)$ & -0.69 \\
\hline Experimental smoker, $\gamma_{14}$ & $-0.09(0.10)$ & -0.84 & $-0.10(0.10)$ & -0.99 \\
\hline Regular smoker, $\gamma_{15}$ & $-0.21(0.13)$ & -1.57 & $-0.22(0.12)$ & -1.75 \\
\hline Lower than average dietary restraint, $\gamma_{16}$ & $-0.09(0.12)$ & -0.77 & - & - \\
\hline Higher than average dietary restraint, $\gamma_{17}$ & $0.03(0.11)$ & 0.24 & - & - \\
\hline Overweight, $\gamma_{16}$ & - & - & $-0.14(0.14)$ & -0.99 \\
\hline \multirow[t]{2}{*}{ Obese, $\gamma_{17}$} & - & - & $-0.02(0.18)$ & 0.12 \\
\hline & \multicolumn{2}{|c|}{ Dietary restraint } & \multicolumn{2}{|l|}{ BMI } \\
\hline Random effect & Variance components & $x^{2}$ & Variance components & $x^{2}$ \\
\hline $\begin{array}{l}\text { Intercept, } v_{0 j} \\
\sigma\end{array}$ & $\begin{array}{l}16.39 \\
23.02\end{array}$ & $3572.70^{\star \star \star}$ & $\begin{array}{l}16.55 \\
23.04\end{array}$ & $3597.40^{\star \star *}$ \\
\hline
\end{tabular}

BMI - body mass index; SE - standard error.

${ }^{\star} P<0.05 ;{ }^{* \star} P<0.01 ;{ }^{\star \star *} P<0.001$.

data sets were contrasted and revealed that reduction in sample size due to missing data did not systematically influence the results.

\section{Results}

\section{Modelling food frequency indices across time}

Frequency of consumption of fruit and vegetables espoused a normal distribution and was therefore modelled as a continuous variable. Testing of the null model showed that the ICC was 0.44 , indicating that slightly more than half of the variance was attributed to within-student changes across time. Students reported consuming fruit and/or vegetables about 17 times per week over the 5-year study. There was a significant amount of interindividual variability in average fruit and vegetable consumption (plausible values ranged from 8 to 25). Modelling of linear change showed that fruit and vegetable consumption decreased over the 5-year period $(P<0.025)$. Students living in rural or in suburban settings reported consuming fruit and vegetables more frequently than those living in urban settings at baseline (respectively 17, 17 and 15 times per week; $P<0.05$ for rural versus urban setting and $P<0.001$ for suburban versus urban setting). Girls reported a slightly higher rate of consumption (18 times per week; $P<0.05$ ).

Frequency of low quality snacking was also normally distributed. Testing of the null model showed that the ICC was 0.33 , suggesting that about two-thirds of the variance was attributed to within-student changes across time. Students reported consuming low quality snacks an average of 10 times per week over 5 years (plausible values ranged from 2 to 17). Consumption of low quality snacks increased over time $(P<0.0001)$. Girls reported lower frequency of low quality snacking than boys at baseline ( 8 versus 9, $P<0.001$ ) and students living in rural settings consumed low quality snacks more frequently than students living in urban settings (10 versus $9, P<0.01$ ). Change in frequency of low quality snacking across time was not associated with sex or place of residence.

Fast food consumption also showed a normal distribution and had no outliers. Students reported consuming fast foods an average of 4 times per week over the 5 years. The $95 \%$ plausible value range extended from 1 to 6 . The majority of variance in this outcome measure was attributed to withinstudent changes across time (ICC $=0.33$ ). Frequency of consumption of fast foods decreased over time both linearly $\left(\gamma_{10}=-0.21, P<0.001\right)$ and quadratically $\left(\gamma_{10}=0.02\right.$, 
Table 3 Results for the model of weekly frequency of low quality snacking and its association with dietary restraint and BM

\begin{tabular}{|c|c|c|c|c|}
\hline \multirow{3}{*}{ Fixed effect } & \multicolumn{2}{|c|}{ Dietary restraint } & \multicolumn{2}{|l|}{ BMl } \\
\hline & Coefficient (SE) & $t$ & Coefficient (SE) & $t$ \\
\hline & \multicolumn{2}{|c|}{ Final estimation of fixed effects } & \multicolumn{2}{|c|}{ Final estimation of fixed effects } \\
\hline Baseline intercept, $\gamma_{00}$ & $9.35(0.40)$ & $23.14^{\star \star \star}$ & $9.19(0.38)$ & $24.0^{\star \star \star}$ \\
\hline Girls, $\gamma_{01}$ & $-0.59(0.21)$ & $-2.74^{\star \star}$ & $-0.73(0.22)$ & $-3.33^{\star * *}$ \\
\hline Vigorous exercise, $\gamma_{02}$ & $-0.10(0.29)$ & -0.35 & $-0.12(0.29)$ & -0.41 \\
\hline Moderate exercise, $\gamma_{03}$ & $-0.48(0.32)$ & -1.51 & $-0.47(0.32)$ & -1.47 \\
\hline Mild exercise, $\gamma_{04}$ & $0.08(0.27)$ & 0.29 & $0.04(0.27)$ & 0.15 \\
\hline Rural setting, $\gamma_{05}$ & $0.70(0.25)$ & $2.86^{\star \star}$ & $0.64(0.25)$ & $2.57^{\star}$ \\
\hline Suburban setting, $\gamma_{06}$ & $-0.19(0.26)$ & -0.73 & $-0.23(0.26)$ & -0.88 \\
\hline Experimental smoker, $\gamma_{07}$ & $0.02(0.30)$ & 0.05 & $-0.06(0.30)$ & -0.21 \\
\hline Regular smoker, $\gamma_{08}$ & $0.63(0.36)$ & 1.74 & $0.60(0.36)$ & 1.65 \\
\hline Lower than average dietary restraint, $\gamma_{09}$ & $-0.53(0.32)$ & -1.63 & - & - \\
\hline Higher than average dietary restraint, $\gamma_{010}$ & $-0.76(0.32)$ & $-2.36^{\star}$ & - & - \\
\hline Overweight, $\gamma_{09}$ & - & - & $-0.61(0.40)$ & -1.51 \\
\hline Obese, $\gamma_{010}$ & - & - & $-0.22(0.54)$ & -0.40 \\
\hline Linear increase, $\gamma_{10}$ & $0.17(0.09)$ & 1.84 & $0.34(09)$ & $3.87^{\star \star *}$ \\
\hline Vigorous exercise, $\gamma_{11}$ & $-0.02(0.07)$ & -0.23 & $-0.02(0.07)$ & -0.31 \\
\hline Moderate exercise, $\gamma_{12}$ & $0.006(0.08)$ & 0.08 & $0.02(0.08)$ & 0.27 \\
\hline Mild exercise, $\gamma_{13}$ & $0.08(0.07)$ & 1.17 & $0.10(0.07)$ & 1.38 \\
\hline Experimental smoker, $\gamma_{14}$ & $-0.009(0.08)$ & -0.13 & $0.001(0.08)$ & 0.01 \\
\hline Regular smoker, $\gamma_{15}$ & $-0.003(0.09)$ & -0.04 & $-0.01(0.09)$ & -0.14 \\
\hline Lower than average dietary restraint, $\gamma_{16}$ & $0.37(0.08)$ & $4.41^{\star * *}$ & - & - \\
\hline Higher than average dietary restraint, $\gamma_{17}$ & $0.11(08)$ & 1.38 & - & - \\
\hline Overweight, $\gamma_{16}$ & - & - & $-0.07(0.10)$ & -0.72 \\
\hline \multirow[t]{2}{*}{ Obese, $\gamma_{17}$} & - & - & $-0.31(0.14)$ & $-2.22^{\star}$ \\
\hline & \multicolumn{2}{|c|}{ Dietary restraint } & \multicolumn{2}{|l|}{ BMI } \\
\hline Random effect & Variance components & $x^{2}$ & Variance components & $x^{2}$ \\
\hline $\begin{array}{l}\text { Intercept, } v_{0 \mathrm{j}} \\
\sigma\end{array}$ & $\begin{array}{r}6.18 \\
12.96\end{array}$ & $2784.05^{\star \star \star}$ & $\begin{array}{r}6.22 \\
13.01\end{array}$ & $2789.84^{\star \star \star}$ \\
\hline
\end{tabular}

$\mathrm{BMI}$ - body mass index; SE - standard error.

${ }^{\star} P<0.05 ;{ }^{* \star} P<0.01 ;{ }^{\star \star \star} P<0.001$.

$P<0.04)$. Both sex and place of residence were associated with fast food consumption at baseline, but not with the time trend. At baseline, girls reported less frequent consumption of fast foods compared with boys $(P<0.0001)$, as did students living in rural settings compared with those living in urban settings $(P<0.02)$.

\section{BMI and dietary restraint}

The overall BMI was normally distributed with a mean of 21.5 (standard deviation (SD) 4.2 ) $\mathrm{kg} \mathrm{m}^{-2}$. Due to the higher level of dietary restraint among females and the positively skewed data, participants were divided into low, average and high restraint groups through a genderspecific tertile split. Mean dietary restraint scores (SD) for the low, average and high restraint groups were 1.31 (0.25), 2.27 (0.29) and 3.37 (0.53) for girls, and 1.08 (0.08), $1.51(0.17)$ and $2.51(0.52)$ for boys. A small but significant correlation between dietary restraint and BMI was found $(r=0.21 ; P<0.001)$.

\section{Associations of food frequency indices with dietary restraint and $\mathrm{BMI}$}

The next set of models tested the association of BMI and dietary restraint measured in the fifth year of the study with baseline and changes in the fruit and vegetable, low quality snacking and fast food consumption indices over time (Tables 2-4). Fruit and vegetable consumption at baseline and changes in consumption over time were not associated with BMI and dietary restraint (Table 2). The addition of physical activity and smoking status did not influence these findings.

BMI was not associated with frequency of low quality snacking at baseline; however, it was associated with changes over time (Table 3). Although overall the sample increased snacking over time, low quality snacking remained relatively stable among those participants classified as obese (Fig. 1a). Dietary restraint was associated with frequency of low quality snacking at baseline and across time. At baseline, high dietary restrainers reported less frequent low quality snacking than average restrainers $(P<0.02)$. Teenagers who reported lower dietary restraint showed greater increase in the frequency of low quality snacks over time $(P<0.001)$ than those with average or high levels of dietary restraint (Table 3 and Fig. 2a). Addition of dummy variables accounting for smoking and activity levels did not change these findings.

The frequency of fast food consumption was associated with BMI at baseline and over time (Table 4). Obese 
Table 4 Results for model of weekly frequency of fast food consumption and its association with dietary restraint and BMI

\begin{tabular}{|c|c|c|c|c|}
\hline \multirow{3}{*}{ Fixed effect } & \multicolumn{2}{|c|}{ Dietary restraint } & \multicolumn{2}{|l|}{ BMI } \\
\hline & Coefficient (SE) & $t$ & Coefficient (SE) & $t$ \\
\hline & \multicolumn{2}{|c|}{ Final estimation of fixed effects } & \multicolumn{2}{|c|}{ Final estimation of fixed effects } \\
\hline Baseline intercept, $\gamma_{00}$ & $4.77(0.24)$ & $20.21^{\star * *}$ & $4.55(0.25)$ & $20.42^{\star \star \star}$ \\
\hline Girls, $\gamma_{01}$ & $-0.66(0.11)$ & $-5.88^{\star \star \star}$ & $-0.65(0.12)$ & $-5.72^{\star \star \star}$ \\
\hline Vigorous exercise, $\gamma_{02}$ & $-20(0.17)$ & -1.18 & $-0.21(0.17)$ & -1.22 \\
\hline Moderate exercise, $\gamma_{03}$ & $-0.50(0.19)$ & $-2.65^{\star \star}$ & $-0.53(0.19)$ & $-2.80^{\star *}$ \\
\hline Mild exercise, $\gamma_{04}$ & $0.23(0.16)$ & 1.43 & $0.20(0.16)$ & 1.21 \\
\hline Rural setting, $\gamma_{05}$ & $-0.04(0.13)$ & -0.28 & $-0.02(0.13)$ & -0.13 \\
\hline Suburban setting, $\gamma_{06}$ & $-0.45(0.14)$ & $-3.34^{\star \star \star}$ & $-0.44(0.14)$ & $-3.22^{\star \star}$ \\
\hline Experimental smoker, $\gamma_{07}$ & $0.16(0.18)$ & 0.88 & $0.12(0.18)$ & 0.67 \\
\hline Regular smoker, $\gamma_{08}$ & $0.58(0.22)$ & $2.66^{\star \star}$ & $0.60(0.22)$ & $2.74^{\star \star}$ \\
\hline Lower than average dietary restraint, $\gamma_{09}$ & $-0.64(0.20)$ & $-3.26^{\star \star \star}$ & - & - \\
\hline Higher than average dietary restraint, $\gamma_{010}$ & $-0.02(0.19)$ & -0.15 & - & - \\
\hline Overweight, $\gamma_{09}$ & - & - & $-0.07(0.22)$ & -0.30 \\
\hline Obese, $\gamma_{010}$ & - & - & $0.77(0.33)$ & $2.32^{\star}$ \\
\hline Linear change, $\gamma_{10}$ & $-0.38(0.17)$ & $-2.20^{*}$ & $-0.30(0.16)$ & -1.89 \\
\hline Vigorous exercise, $\gamma_{11}$ & $0.06(0.13)$ & 0.48 & $0.07(0.14)$ & 0.54 \\
\hline Moderate exercise, $\gamma_{12}$ & $0.17(0.15)$ & 1.16 & $0.19(0.16)$ & 1.29 \\
\hline Mild exercise, $\gamma_{13}$ & $-0.16(13)$ & -1.28 & $-0.14(0.13)$ & -1.010 \\
\hline Experimental smoker, $\gamma_{14}$ & $0.01(14)$ & 0.09 & $0.03(0.15)$ & 0.23 \\
\hline Regular smoker, $\gamma_{15}$ & $-0.32(0.17)$ & -1.90 & $-0.34(0.19)$ & -1.98 \\
\hline Lower than average dietary restraint, $\gamma_{16}$ & $0.35(0.15)$ & $2.29^{*}$ & - & - \\
\hline Higher than average dietary restraint, $\gamma_{17}$ & $-0.04(0.15)$ & -0.27 & - & - \\
\hline Overweight, $\gamma_{16}$ & - & - & $-0.15(0.19)$ & 0.75 \\
\hline Obese, $\gamma_{17}$ & - & - & $-0.60(0.25)$ & $-2.36^{\star}$ \\
\hline Quadratic change, $\gamma_{20}$ & $0.03(0.03)$ & 1.065 & $0.02(0.03)$ & 0.79 \\
\hline Vigorous exercise, $\gamma_{21}$ & $-0.02(0.02)$ & -0.68 & $-0.02(0.02)$ & -0.71 \\
\hline Moderate exercise, $\gamma_{22}$ & $-0.02(0.03)$ & -0.78 & $-0.02(0.03)$ & -0.88 \\
\hline Mild exercise, $\gamma_{23}$ & $0.04(0.02)$ & 1.51 & $0.03(0.02)$ & 1.40 \\
\hline Experimental smoker, $\gamma_{24}$ & $-00(0.03)$ & -0.30 & $-0.01(0.03)$ & -0.38 \\
\hline Regular smoker, $\gamma_{25}$ & $-0.05(0.03)$ & 1.70 & $0.056(0.03)$ & 1.76 \\
\hline Lower than average dietary restraint, $\gamma_{26}$ & $-0.04(0.03)$ & -1.50 & - & - \\
\hline Higher than average dietary restraint, $\gamma_{27}$ & $0.00(0.03)$ & 0.16 & - & - \\
\hline Overweight, $\gamma_{26}$ & - & - & $0.02(0.04)$ & -0.50 \\
\hline \multirow[t]{2}{*}{ Obese, $\gamma_{27}$} & - & - & $-0.08(0.05)$ & 1.68 \\
\hline & \multicolumn{2}{|c|}{ Dietary restraint } & \multicolumn{2}{|l|}{ BMI } \\
\hline Random effect & Variance components & $x^{2}$ & Variance components & $x^{2}$ \\
\hline $\begin{array}{l}\text { Intercept, } v_{0 j} \\
\sigma\end{array}$ & $\begin{array}{l}1.56 \\
3.89\end{array}$ & $2540.10^{\star \star}$ & $\begin{array}{l}1.56 \\
3.90\end{array}$ & $2531.39^{\star \star \star}$ \\
\hline
\end{tabular}

$\mathrm{BMI}$ - body mass index; SE - standard error.

${ }^{\star} P<0.05 ;{ }^{\star \star} P<0.01 ;{ }^{* \star \star} P<0.001$.

students reported a higher consumption of fast food at baseline $(P<0.05)$, which declined along with the rest of the sample, but at a significantly faster rate $(P<0.05)$ (Fig. 1b). Students with low dietary restraint reported less frequent fast food consumption than those with average dietary restraint at baseline $(P<0.001)$ (Table 4$)$. The consumption of fast food decreased over time for the entire sample except for individuals reporting low dietary restraint $(P<0.019)$ (see Table 4 and Fig. $2 \mathrm{~b})$. The presence of smoking and activity levels did not influence the time trend between dietary restraint, BMI and fast food consumption.

\section{Discussion}

The first aim of this longitudinal study was to describe changes in dietary behaviours with respect to fruit and vegetable consumption, low quality snacking and fast food consumption over a 5-year transitional phase between childhood and adolescence (pre-teen to teen), namely from $9 / 10$ years (fourth graders) to $14 / 15$ years (ninth graders) of age. The second aim was to explain how these changes might be associated with dietary restraint and the occurrence of overweight and obesity measured at the end of the 5-year follow-up. Results show an overall decrease in the frequency of fruit and vegetable consumption, an increase in the frequency of low quality snacking and a decrease in the frequency of fast food consumption. Girls reported higher frequency of fruit and vegetable consumption, and lower frequency of both low quality snacking and fast food consumption than boys. In comparison with students living in rural or suburban settings, students living in urban areas consumed more fast food and less fruit and vegetables. Obesity was associated with more stable low quality snacking over time, and with higher fast food 

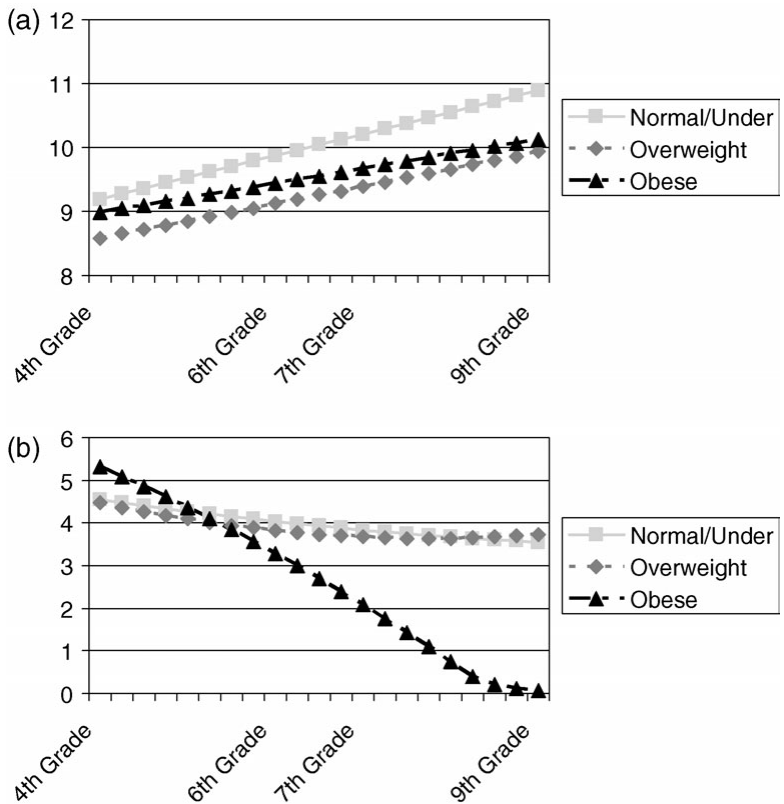

Fig. 1 Weekly frequency of low quality snacking (a) and fast food consumption (b) across a 5-year period among youths with nor$\mathrm{mal} /$ underweight, overweight and obesity

consumption at baseline but a greater decline in fast food consumption over time (Fig. 1). Low dietary restraint was associated with a greater frequency of both fast food consumption and low quality snacking by the end of the study period (Fig. 2). In particular, students with low dietary restraint in the ninth grade demonstrated incremental increases in low quality snacking over time. Students who reported low dietary restraint maintained a stable consumption of fast food over time whereas the rest of the sample decreased consumption of fast food over time.
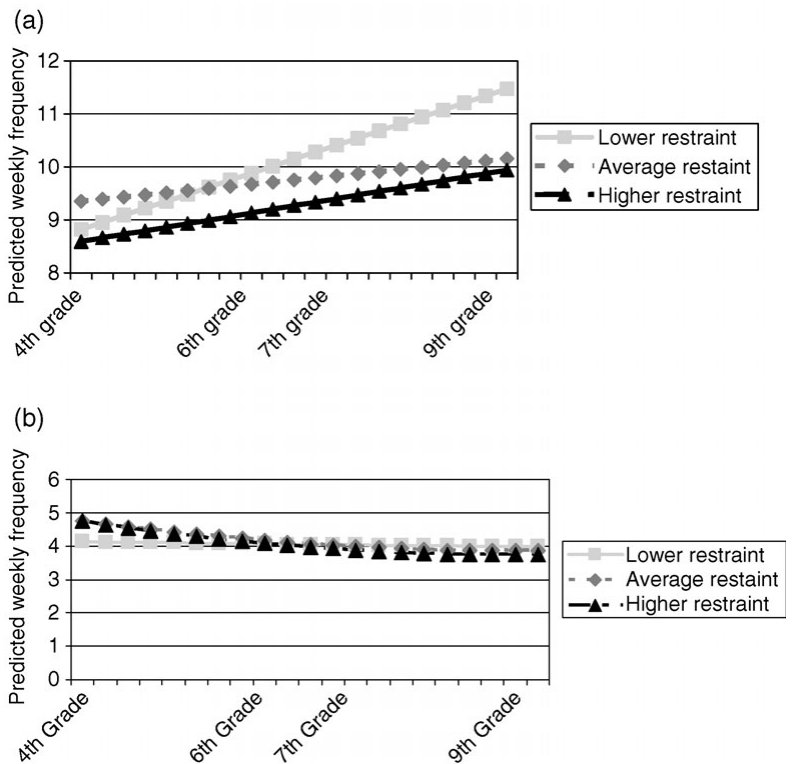

Fig. 2 Weekly frequency of low quality snacking (a) and fast food consumption (b) across a 5-year period among youths with lower, average and higher dietary restraint
Thus, at the end of follow-up, consumption of fast food was higher among low dietary restrainers than among average and high restrainers (Fig. 2b).

Longitudinal evidence suggests a decline in quality in eating patterns during adolescence ${ }^{17,47}$. Results reported in this study are in line with these findings for fruit and vegetable consumption and for low quality snacking. In particular, the dietary trajectories of boys and those living in rural areas may suggest a greater occurrence of unhealthy dietary patterns over time among these groups of individuals. However, the youth in our study demonstrated an overall decline in fast food consumption from a mean of 5.0 fast food servings weekly to 3.0 weekly servings. This finding is at odds with the literature reporting that fast food intake increases with increasing age ${ }^{48}$. It is possible that the students in our study replaced meals (i.e. chicken and hamburgers) with snacks (i.e. salty snacks and soft drinks), a phenomenon which is becoming more prevalent among adolescents ${ }^{49}$. Alternatively, this effect could be caused because the food-frequency questionnaire used in this study did not include pizza, a fast food item whose consumption among adolescents has increased ${ }^{49}$.

Our sample is characterised by slightly lower occurrence of obesity and overweight $(19.9 \%)$ relative to the general population of Canadian and Quebec youth ${ }^{50}$. The Canadian Community Health Survey (2005) reports the national average of overweight and obese Canadian youth to be $26.3 \%$. This prevalence is slightly lower in the province of Quebec (22.6\%). It is possible that the low participation rate within our study from among urban families has influenced the lower proportion of overweight youth found in our sample. The overall mean dietary restraint in our study (2.3 for girls and 1.5 for boys) is similar to findings in other studies using the same psychometric tool in the adolescent population ${ }^{51}$.

Contrasted with other restrictive dietary practice scales which measure the presence of eating boundaries and are associated with the maintenance of ideal weight ${ }^{52}$, dietary restraint measured with the DEBQ among adolescents has been found to be associated with unhealthy weight control measures ${ }^{53}$, overeating in response to stress ${ }^{54,55}$, negative attitudes toward food ${ }^{22}$ and weight gain in interaction with stress ${ }^{56}$. In addition, higher dietary restraint among adolescent females is associated with higher body weight but lower energy intake ${ }^{51}$. Higher dietary restraint in our study was associated with less fast food consumption and low quality snacking by the ninth grade. Research using food grouping similar to ours, such as low quality snacking and energy-dense foods, has found associations with weight status ${ }^{57,58}$. Although our results related to fast food consumption at baseline among obese students are in line with these studies, the decline found in fast food consumption and low quality snacking may be surprising. Although it is possible that this finding is due to the methodological limitations in our measures, whereby obese individuals are snacking or eating fast 
foods not reported in our survey, counterintuitive findings related to weight status and diet among youth are not uncommon $^{8,9}$. Findings in this regard have been explained in terms of reporting bias whereby youth with weight problems are increasingly concerned with body image and more inclined to underreport fat consumption ${ }^{8,35}$. These findings also correspond with suggestions that obese children are more likely to be practising dietary restraint on the one hand, but eating in response to external and negative emotional cues, on the other ${ }^{59}$. Underreporting in this sense might result from subconscious overeating, particularly with regard to fat, which is more likely than other macronutrients to lead to passive overconsumption $^{60}$. Alternatively, obese children might be trying to lose weight and thus eating fewer low quality snacks.

Additional limitations to this study need to be underscored. As in most longitudinal research, subject attrition occurred. It is possible that those persons who were not followed-up had different eating behaviour patterns from those who were tracked. Also, we did not measure BMI and dietary restraint until grade 9 for feasibility reasons. It is likely that a more differentiated picture of the evolution of eating behaviours would have emerged had we had the opportunity to link up eating behaviour changes over time with changes in weight status and tendencies to restrain food intake over time. In this respect, associations in evolution in dietary behaviours with dietary restraint and BMI are crosssectional, and do not suggest causality.

Despite these limitations, we conclude that eating behaviours do evolve from late childhood to early adolescence and that some of these changes are associated with psychosocial tendencies such as dietary restraint. Our results suggest a need for continued exploration into overweight and obesity as a complex process which goes beyond energy balance equations to include psychosocial processes with intimate ties to eating behaviour. The findings presented show dietary restraint to be associated with dietary behaviours and their evolution during adolescence, and thus support research suggesting that maladaptive eating style practices such as dietary restraint may be implied in the development of overweight and obesity. In particular, we show that links between this psychosocial phenomenon and eating behaviour develop early in adolescence. Future research is required to replicate these findings and to explain further the processes through which developmental change and environmental exposure to eating cues interact towards producing change in eating behaviours and differential associations with dietary restraint.

\section{Acknowledgements}

Sources of funding: Research reported herein was supported by Operating Grant \# 97030 P-35878-PSB38212 from the Medical Research Council of Canada and \#6605-5254-002 from the National Health Research
Development Program. S.B. is a recipient of a CIHR Doctoral Research Award.

Conflict of interest declaration: None of the authors have a competing interest regarding these data being published.

Authorship responsibilities: S.B. was awarded a summer bursary from the Équipe de recherche en promotion de la santé (Université de Montréal, Faculté de médecine) in order to complete data analysis and write-up of this research. Analysis and write-up were completed under the direct supervision of L.G. G.P. and L.P. contributed to the conceptual design of the analyses and write-up of the article, through editing and input to presentation.

\section{References}

1 French SA, Story M, Neumark-Sztainer D, Fulkerson JA, Hannan P. Fast food restaurant use among adolescents: associations with nutrient intake, food choices and behavioral and psychosocial variables. International Journal of Obesity and Related Metabolic Disorders 2001; 25: 1823-33.

2 Janssen I, Katzmarzyk PT, Boyce WF, King MA, Pickett W. Overweight and obesity in Canadian adolescents and their associations with dietary habits and physical activity patterns. Journal of Adolescent Health 2004; 35: 360-7.

3 Bell A, Kremer P, Magarey AM, Swinburn B. Contribution of noncore foods and beverages to the energy intake and weight status of Australian children. European Journal of Clinical Nutrition 2005; 59: 639-45.

4 Troiano RP, Briefel RR, Carroll MD, Bialostosky K. Energy and fat intakes of children and adolescents in the United States: data from the National Health and Nutrition Examination Surveys. American Journal of Clinical Nutrition 2000; 72(5 Suppl.): 1343S-53S.

5 Demory-Luce D, Morales M, Nicklas T, Baranowski T, Zakeri I, Berenson G. Changes in food group consumption patterns from childhood to young adulthood: the Bogalusa heart study. Journal of the American Dietetic Association 2004; 104: 1684-91.

6 Prentice A, Jebb S. Energy intake/physical activity interactions in the homeostasis of body weight regulation. Nutrition Reviews 2004; 62: S98-104.

7 Stubbs CO, Lee AJ. The obesity epidemic: both energy intake and physical activity contribute. Medical Journal of Australia 2004; 181: 489-91.

8 Magarey AM, Daniels LA, Boulton TJ, Cockington RA. Does fat intake predict adiposity in healthy children and adolescents aged 2-15 y? A longitudinal analysis. European Journal of Clinical Nutrition 2001; 55: 471-81.

9 Remer T, Dimitriou T, Kersting M. Does fat intake explain fatness in healthy children? European Journal of Clinical Nutrition 2002; 56: 1046-7.

10 Davison KK, Markey CN, Birch LL. A longitudinal examination of patterns in girls' weight concerns and body dissatisfaction from ages 5 to 9 years. International Journal of Eating Disorders 2003; 33: 320-32.

11 Carper JL, Orlet Fisher J, Birch LL. Young girls' emerging dietary restraint and disinhibition are related to parental control in child feeding. Appetite 2000; 35: 121-9.

12 Fisher JO, Birch LL. Eating in the absence of hunger and overweight in girls from 5 to $7 \mathrm{y}$ of age. American Journal of Clinical Nutrition 2002; 76: 226-31.

13 Wardle J, Steptoe A, Oliver G, Lipsey Z. Stress, dietary restraint and food intake. Journal of Psychosomatic Research 2000; 48: 195-202. 
14 Cusatis DC, Chinchilli VM, Johnson-Rollings N, Kieselhorst $\mathrm{K}$, Stallings VA, Lloyd T. Longitudinal nutrient intake patterns of US adolescent women: the Penn state young women's health study. Journal of Adolescent Health 2000; 26: 194-204.

15 Feunekes GI, de Graaf C, Meyboom S, van Staveren WA. Food choice and fat intake of adolescents and adults: associations of intakes within social networks. Preventive Medicine 1998; 27: 645-56.

16 Cusatis DC, Shannon BM. Influences on adolescent eating behavior. Journal of Adolescent Health 1996; 18 $27-34$.

17 Lytle LA, Seifert S, Greenstein J, McGovern P. How do children's eating patterns and food choices change over time? Results from a cohort study. American Journal of Health Promotion 2000; 14: 222-8.

18 Lien N, Lytle LA, Klepp KI. Stability in consumption of fruit, vegetables, and sugary foods in a cohort from age 14 to age 21. Preventive Medicine 2001; 33: 217-26.

19 Drewnowski A, Durth C, Rahaim J. Taste preferences in human obesity: environmental and familial factors. American Journal of Clinical Nutrition 1991; 54: 635-41.

20 Kern D, McPhee L, Fisher JO, Johnson S, Birch LL. The postingestive consequences of fat condition preferences for flavors associated with high dietary fat. Physiological Behavior 1993; 54: 71-6.

21 Birch LL, Fisher JO, Davison KK. Learning to overeat: maternal use of restrictive feeding practices promotes girls' eating in the absence of hunger. American Journal of Clinical Nutrition 2003; 78: 215-20.

22 Wardle J, Marsland L, Sheikh Y, Quinn M, Fedoroff I, Ogden J. Eating style and eating behaviour in adolescents. Appetite 1992; 18: 167-83.

23 Irving LM, Neumark-Sztainer D. Integrating the prevention of eating disorders and obesity: feasible or futile? Preventive Medicine 2002; 34: 299-309.

24 Hill AJ. Does dieting make you fat? British Journal of Nutrition 2004; 92(1 Suppl.): S15-8.

25 Braet C, Van Strien T. Assessment of emotional, externally induced and restrained eating behaviour in nine to twelveyear-old obese and non-obese children. Behaviour Research and Therapy 1997; 35: 863-73.

26 Hill AJ, Franklin JA. Mothers, daughters and dieting: investigating the transmission of weight control. British Journal of Clinical Psychology 1998; 37: 3-13.

27 Shapiro S, Newcomb M, Loeb TB. Fear of fat, disregulated-restrained eating, and body-esteem: prevalence and gender differences among eight- to ten-yearold children. Journal of Clinical Child Psychology 1997; 26: $358-65$.

28 Rosen DS, Gross J, Vara L. Psychological adjustment of adolescents attempting to lose or gain weight. Journal Consulting and Clinical Psychology 1987; 55: 742-7.

29 Killen J, Taylor C, Hayward C. Pursuit of thinness and onset of eating disorder symptoms in a community of adolescent girls: a three year prospective analysis. International Journal of Eating Disorders 1994; 16: 227-38.

30 Fisher L, Soubhi H, Mansi O, Paradis G, Gauvin L, Potvin L. Family process in health research: extending a family typology to a new cultural context. Health Psychology 1998; 17: $358-66$.

31 Frohlich KL, Potvin L, Chabot P, Corin E. A theoretical and empirical analysis of context: neighbourhoods, smoking and youth. Social Science \& Medicine 2002; 54: $1401-17$

32 King A, Wold B, Tudor-Smith C, Harel Y. The health of youth. A cross-national survey. WHO Regional Publications. European Series 1996; 69: 1-222.

33 Vereecken CA, Maes L. A Belgian study on the reliability and relative validity of the Health Behaviour in School-aged
Children food-frequency questionnaire. Public Health Nutrition 2003; 6: 581-8.

34 Hammond J, Nelson M, Chinn S, Rona RJ. Validation of a food frequency questionnaire for assessing dietary intake in a study of coronary heart disease risk factors in children. European Journal of Clinical Nutrition 1993; 47: $242-50$.

35 Livingstone MB, Robson PJ. Measurement of dietary intake in children. Proceedings of the Nutrition Society 2000; 59: 279-93.

36 Cartwright M, Wardle J, Steggles N, Simon AE, Croker H, Jarvis MJ. Stress and dietary practices in adolescents. Health Psychology 2003; 22: 362-9.

37 Kuczmarski R, Ogden C, Grummer-Strawn L, Flegal K, Guo S, Wei R, et al. CDC Growth Charts: United States. Number 314. Hyattsville, MD: National Center for Health Statistics, 2000.

38 Barlow SE, Dietz WH. Obesity evaluation and treatment: expert committee recommendations. The Maternal and Child Health Bureau, Health Resources and Services Administration and the Department of Health and Human Services. Pediatrics 1998; 102: E29.

39 Dietz W, Bellizzi M. Introduction: the use of body mass index to assess obesity in children. American Journal of Clinical Nutrition 1999; 70: 123s-5s.

40 Brener ND, McManus T, Galuska DA, Lowry R, Wechsler H. Reliability and validity of self-reported height and weight among high school students. Journal of Adolescent Health 2003; 32: $281-7$.

41 Goodman E, Hinden BR, Khandelwal S. Accuracy of teen and parental reports of obesity and body mass index. Pediatrics 2000; 106: 52-8.

42 Strauss RS. Comparison of measured and self-reported weight and height in a cross-sectional sample of young adolescents. International Journal of Obesity and Related Metabolic Disorders 1999; 23: 904-8.

43 Van Strien T, Frijters J, Bergers G, Defares P. The Dutch Eating Behaviour Questionnaire (DEBQ) for assessment of restrained, emotional, and external eating behaviour. International Journal of Eating Disorders 1986; 5: 295-315.

44 Lluch A, Kahn J, Sticker-Drongrand A, Ziegler L, Drouin P, Méjean L. Internal validation of a French version of the Dutch Eating Behaviour Questionnaire. European Psychiatry 1996; 11: 198-203.

45 Allison D, Franklin R. The readability of three measures of dietary restraint. Psychotherapeutic Private Practice 1993; 12: $53-7$.

46 Wardle J. Restraint, body image and food attitudes in children from 12 to 18 y. Appetite 1986; 7: 209-17.

47 Morton J, Guthrie J. Changes in children's total fat intakes and their food group sources of fat, 1989-91 versus 199495: implications for diet quality. Family Economics and Nutrition Review 1998; 11: 44-57.

48 Schmidt M, Affenito SG, Striegel-Moore R, Khoury PR, Barton $\mathrm{B}$, Crawford P, et al. Fast-food intake and diet quality in black and white girls: the National Heart, Lung, and Blood Institute Growth and Health Study. Archives of Pediatrics $\mathcal{E}$ Adolescent Medicine 2005; 159: 626-31.

49 Nielsen S, Siega-Riz A, Popkin B. Trends in food locations and sources among adolescents and young adults. Preventive Medicine 2002; 35: 107-13.

50 Statistics Canada. Canadian Community Health Survey Nutrition General Health Component. Ottawa: Minister of Industry, 2005.

51 Lluch A, Herbeth B, Méjean L, Siest G. Dietary intakes, eating style and overweight in the Stanislas family study. International Journal of Obesity and Related Metabolic Disorders 2000; 24: 1493-9.

52 Wardle J, Griffith J. Socioeconomic status and weight control practices in British adults. Journal of Epidemiology and Community Health 2001; 55: 185-90. 
53 Wardle J, Robb KA, Johnson F, Griffith J, Brunner E, Power C, Tovee M. Socioeconomic variation in attitudes to eating and weight in female adolescents. Health Psychology 2004; 23: $275-82$.

54 Stice E, Cameron R, Killen J, Hayward C, Taylor C. Naturalistic weight-reduction efforts prospectively predict growth in relative weight and onset of obesity among female adolescents. Journal of Consulting and Clinical Psychology 1999; 61: 967-74.

55 Roemmich JN, Wright SM, Epstein LH. Dietary restraint and stress-induced snacking in youth. Obesity Research 2002; 10: 1120-6.

56 Tiggemann M. Dietary restraint and self-esteem as predictors of weight gain over an 8-year time period. Eating Behaviors 2004; 5: 251-9.
57 Drapeau V, Despres JP, Bouchard C, Allard L, Fournier G, Leblanc $\mathrm{C}$, et al. Modifications in food-group consumption are related to long-term body-weight changes. American Journal of Clinical Nutrition 2004; 80: 29-37.

58 Nicklas TA, Yang SJ, Baranowski T, Zakeri I, Berenson G. Eating patterns and obesity in children. The Bogalusa heart study. American Journal of Preventive Medicine 2003; 25: $9-16$.

59 Braet C, Van Strien T. Assessment of emotional, externally induced and restrained eating behaviour in nine to twelveyear-old obese and non-obese children. Behaviour Research and Therapy 1997; 35: 863-73.

60 World Health Organization (WHO). Report of a WHO Consultation on Obesity. Obesity: Preventing and Managing the Global Epidemic. Geneva: WHO, 1998. 